\title{
The Effects of Pre-Reading Activities on Reading Comprehension of Iranian EFL Learners
}

\author{
Nahid Nemati Moghaddam \\ Department of English Language, Ardabil Science and Research Branch, Islamic Azad University, Ardabil, Iran \\ $\&$ \\ Department of English Language, Ardabil Branch, Islamic Azad University, Ardabil, Iran \\ E-mail: nahid.nematimogadam2@gmail.com \\ Asgar Mahmoudi (Corresponding author) \\ Department of English Language, Ardabil Branch, Islamic Azad University, Ardabil, Iran \\ E-mail: Mahmoudi301@gmail.com
}

Doi:10.7575/aiac.alls.v.7n.3p.235

Received: 15/02/2016

URL: http://dx.doi.org/10.7575/aiac.alls.v.7n.3p.235

Accepted: 09/04/2016

\begin{abstract}
This study investigated the effects of three types of pre-reading activities (movie-watching, vocabulary presentation, and pre-reading summarization) on the reading comprehension of 76 elementary-level EFL Iranian learners. The participants were randomly assigned to one control and three experimental conditions and then a pretest was given to them. After completing the initial stages, participants in all groups read the same passages under different conditions for seven sessions. Each group was then given a posttest. After that, Paired-samples T-tests were run to find out if the participants had made any significant gains from the pretests to the posttests, which proved to be the case. Results of a One-way ANOVA also revealed that students who had received treatments were better in performance than those who had not received any treatment. Finally, the Split-plot ANOVA test run on the results of the posttest and delayed posttest indicated that there was a slight decrease overtime in scores of the students in two of the experimental conditions which was the result of both instruction or class type and its interaction with time but not time itself.
\end{abstract}

Keywords: movie watching, vocabulary presentation, pre-reading summarization

\section{Introduction}

Iranian learners of English as a foreign language learn English in the classroom environment but cannot use it out of the class or in real-life situations. Therefore, reading is an essential source of input to them. Also, a lot of teachers do not know how to engage students in reading activities or they find it difficult. This means that a lot of energy is wasted and the point of teaching texts or passages is missed. This study investigated specifically the extent to which pre-reading activities might improve EFL learners' reading comprehension.

\subsection{Research Hypotheses}

1.2 The research hypotheses of this study were:

H01- Pre-reading activities do not affect students' reading comprehension from pretests to posttests.

H02- There is no difference in the effectiveness of the three pre-reading activities of watching movies, vocabulary presentation, and pre-reading summarization.

H03- Participants' scores in different groups change significantly from posttests to delayed posttests as a result of passage of time.

\subsection{Participants}

The initial pool of the participants composed of 90 students who were selected randomly from among first and second grade high school students in Ardabil, Iran. All participants were female and native Iranian students and their ages ranged from 14 to 16 . In order to determine the students' proficiency level, a proficiency test was given to them prior to the beginning of the research and 14 students, who missed the test's cut-point, were excluded from the study. The students were then randomly assigned to 4 groups of 19 with the non-qualifying students distributed evenly among them. There were three experimental groups and one control group. The groups were called Movie Watching Group (MWG), Vocabulary Presentation Group (VPG), Pre-reading Summarization Group (PSG), and No Treatment Group (NTG). The participants were at the elementary level of English proficiency and the courses were offered to them for two months. Six sessions were spent on piloting of the study and giving pretests and posttests to the participants. The actual treatments lasted for seven sessions. 


\subsection{Research Design}

With respect to what was said, it is clear that the design of the study had been a true experimental design but since the comparisons were made within and between groups, it also can be called a within-between groups design. On the other hand, measuring the effect of time means that the design had also been a repeated measures design. The overall name that can be given to the design of the study, therefore, is a within-between-repeated-measures design.

\section{Review of the Related Literature}

Pre-reading activities are activities that are used with the students before teaching of the actual reading materials. Prereading activities, prepare students for better comprehension by making them familiar with the topic, vocabulary, or structures that they may come across in the text (Bilokcuoglu, 2011). For Tudor (1990) pre-reading activities refer to "the range of pedagogical techniques whereby learners are engaged, prior to their main processing of a target text, in text-related conceptual activities designed to help them to process their text in a more meaningful manner" (P. 96). Haque (2010) sees pre-reading activities as warm-up activities which prepare students for reading tasks. The activities do not have a set format and may differ in their length. They may also differ in terms of the amount of input that is needed for students to complete them. Ausubel (1963) views pre-reading activities as 'advance-organizers'. Advance organizers, provide the necessary information for the learners and activate their existing knowledge to assist in processing and retaining of the text.

Hyde (2002), likewise, highlights the facilitative role of pre-reading activities in setting up the context and activation of the reader's prior knowledge. Along the same lines, Norris and Phillips (1987) emphasize that comprehension occurs only when the reader is able to set in motion his or her background knowledge. They believe that prior knowledge is essential for interpreting an author's message. Cook (1997) refers to schema theory and underlines the necessity of providing students with the background knowledge they need in order to help in solving their comprehension problems. The facilitative effects of activating readers' prior knowledge in understanding new texts is underscored by many including Langer (1981) and Johnson (1982). According to these researchers, pre-reading activities make the reading task easier in addition to preparing the readers for the upcoming concepts and connecting the new and old ones. The main function of pre-reading activities, therefore, is to activate prior knowledge structures or make them accessible to the reader that lacks them (Yusuf, 2011).

Anjomshoa and Sadighi (2015) researched the effects of vocabulary definitions, text summary and pre-passage questions, as pre-reading activities, on Iranian EFL learners' reading comprehension. They selected 200 subjects, one hundred intermediate and one hundred advanced, based on the results of a placement test. Two intermediate level and two advanced level texts were chosen for reading purposes. The gathered data were analyzed using ANOVA and a follow up Tukey's HSD which showed that the experimental groups had outperformed the control group with textsummary group performing much better than the other three groups.

Even though the majority of studies show a significant positive effect for using pre-reading activities in regard to comprehension, there are studies which have found no significant difference between pre-reading and no pre-reading situations. Jahangard, Moinzadeh and Karimi (2011), for example, studied the effects of grammar and vocabulary preteaching, from the stand point of schema theory. The two strategies were used as two types of pre-reading activities, and their effects on EFL learners' reading comprehension were measured. Students in group A received grammar preteaching as support for their reading comprehension, whereas students in group B underwent vocabulary pre-teaching. Students in the control group received no particular pre-teaching support. The results of the analysis after the posttest showed no significant difference among the three groups. Strangely enough, the grammar group performed worse than the control group.

\section{Method}

In the first session, all learners took a proficiency test to choose the elementary level learners only. The elementary level learners were assigned to four groups. The next step was to administer the pretest to determine the existing knowledge of participants before receiving any kind of instruction. The treatment in each group comprised of seven sessions that lasted for 2 months. Each session consisted of three stages, pre-reading, while reading, and post-reading activities.

In the movie-watching group (MWG), the movies were selected based on the content and level of language difficulty and presented one in every session. As the students watched the movies, the teacher stopped them occasionally to check for comprehension. After watching each movie, they received the reading passage which was followed by the teacher reading it. In the post reading stage, the students were asked to answer some oral questions, and they were given a simple assignment to do within 2-3 min. Then, each student was asked to explain the movie or reading passage.

In the pre-reading vocabulary group (PVG), some lexical items were singled out and presented by the teacher using their synonyms or paraphrases. The words were selected on the basis of their importance and likelihood that they were unknown to the students. All these lexical items were written on the whiteboard with their definitions or synonyms. The words were defined and explained in context.

In the pre-reading summarization group (PSG), the summary of the related passage was written on the whiteboard before reading the full-length text. This activity took ten minutes like the pre-reading activities in other groups. There was no pre-reading stage in the NTG or no-treatment group. They received a passage and began reading the task immediately.

\section{Results}

After assigning the students to different groups and administering the pretest, normality of the obtained scores, which is an important assumption of parametric tests, was checked by running 1-Sample K-S tests. Table 1 shows the results of these tests. 
Table 1. Normality of Scores' Distributions in Pretest

\begin{tabular}{lllll}
\hline & Pretest group one & Pretest group two & Pretest group three & Pretest group four \\
\hline $\mathrm{N}$ & 19 & 19 & 19 & 19 \\
\hline $\begin{array}{l}\text { Asymp. } \\
\begin{array}{l}\text { Sig. (2- } \\
\text { tailed) }\end{array}\end{array}$ & .221 & .318 & .868 & .711 \\
\hline
\end{tabular}

a. Test distribution is normal

The larger than .05 values in Asymp. Sig. (2-tailed) row mean that the assumption of normality had not been violated in any of the distributions of scores.

After making sure that the scores were normally distributed, a One-way ANOVA accompanied by a Levene's Test of Equality of Error Variances was run to see if the groups were homogeneous and the means of their scores were not substantially different from each other. The results of these tests are given in Tables 2 and 3 below.

\begin{tabular}{llll}
\multicolumn{4}{l}{ Table 2. Test of Equality of Variances } \\
\hline Levene's Statistic & df1 & df2 & Sig. \\
\hline 2.035 & 3 & 72 & .117 \\
\hline
\end{tabular}

Table 3. Comparing Scores in Pretest

\begin{tabular}{llllll}
\hline Squares & Sum of & & $\begin{array}{l}\text { Mean } \\
\text { Square }\end{array}$ & F & Sig. \\
\hline Between groups & 32.145 & 3 & 10.715 & 2.489 & .067 \\
Within groups & 309.895 & 72 & 4.304 & & \\
Total & 342.039 & 75 & & & \\
\hline
\end{tabular}

Based on the Sig value displayed in Table 2, it can be concluded that the assumption of homogeneity of variances had not been violated with $P=.117>.05$. Table 3 shows that the Sig. value is equal to .067 which is larger than .05 . This means that, at the beginning of the study there had not been any significant difference(s) among the groups in terms of their reading comprehension ability.

It was after these preliminary analyses that the actual study began. The treatments were offered to the participants for seven weeks and each group was given a posttest afterwards which was the exact replica of the pretest administered at the beginning of the course. The normality of the scores' distributions, as in the pretest, were checked using 1-sample $\mathrm{K}-\mathrm{S}$ tests to see if they were appropriate for running Paired-samples T-tests. The distributions of scores proved to be normal at this stage too.

Paired-samples T-tests could show if the participants had made any significant gains from the pretests to the posttests with respect to their reading comprehension ability. The results of these tests are given in Table 4 .

Table 4. Paired-samples T-tests Comparing Pretest and Posttest Results

\begin{tabular}{|c|c|c|c|c|c|c|c|c|}
\hline & & \multicolumn{4}{|c|}{ Paired Differences } & \multirow[b]{3}{*}{$\mathrm{t}$} & \multirow[b]{3}{*}{$\mathrm{df}$} & \multirow{3}{*}{$\begin{array}{l}\text { Sig. } \\
(2- \\
\text { tailed })\end{array}$} \\
\hline & & \multirow[b]{2}{*}{ Mean } & \multirow{2}{*}{$\begin{array}{l}\text { Std. } \\
\text { Deviatio } \\
\mathrm{n}\end{array}$} & \multicolumn{2}{|c|}{$\begin{array}{l}95 \% \text { Confidence } \\
\text { Interval of the } \\
\text { Difference }\end{array}$} & & & \\
\hline & & & & Lower & Upper & & & \\
\hline Pair 1 & Pretest control group - & 5.5263 & 3.13343 & -3.16888 & -.62059 & -3.124 & 18 & .006 \\
\hline & Posttest control group & 7.4211 & 2.61015 & & & & & \\
\hline Pair 2 & Pretest vocabulary group & 4.6842 & 1.79668 & -7.59104 & -5.35632 & -12.172 & 18 & .000 \\
\hline & $\begin{array}{l}\text { - Posttest vocabulary } \\
\text { group }\end{array}$ & 11.1579 & 2.65127 & & & & & \\
\hline Pair 3 & Pretest movie group - & 6.4737 & 1.71167 & -8.03078 & -5.86396 & -13.472 & 18 & .000 \\
\hline & Posttest movie group & 13.4211 & 1.42657 & & & & & \\
\hline Pair 4 & Pretest summary group - & 5.9474 & 2.24781 & -5.22869 & -2.98184 & -7.677 & 18 & .000 \\
\hline & Posttest summary group & 10.0526 & 2.59216 & & & & & \\
\hline
\end{tabular}

The Sig value obtained for the control group shows a significant increase in the participants' mean scores from the pretest to the posttest. There had also been statistically significant increases in the participants' mean scores from the 
pretests to the posttests in pre-reading vocabulary, movie watching, and summarization groups all with $P$ values equal to .000 . These findings reject the study's first null hypothesis.

To test the study's second null hypothesis, we needed to compare all of the four groups' results after finishing the course and figuring out if the gains by the groups were significantly different from each other. A One-way ANOVA was run for this purpose along with a homogeneity and a Scheffee post-hoc tests.

The homogeneity test showed that this assumption had not been violated with $P=.116>.05$. The ANOVA test also showed a significant difference among the groups at $P=.000>.05$ level at the posttest stage. Tables 5 and 6 shows the results of these tests.

Table 5. Homogeneity of the groups in Posttest

\begin{tabular}{llll}
\hline Scores post & & & \\
\hline Levene's Statistic & df1 & df2 & Sig. \\
\hline 2.036 & 3 & 72 & .116 \\
\hline
\end{tabular}

Table 6. Comparing Group Means at Posttest

\begin{tabular}{llllll}
\hline & \multicolumn{2}{l}{ Sum of Squares } & df & Mean Square F & Sig. \\
\hline Between Groups & 354.250 & 3 & 118.083 & 20.90 & .000 \\
& & & & 3 & \\
Within Groups & 406.737 & 72 & 5.649 & & \\
Total & 760.987 & 75 & & & \\
\hline
\end{tabular}

ANOVA, however, is an omnibus test and does not show where the difference(s) lie when we compare groups. To find out about the location of differences a Scheffe post hoc test was utilized the results of which are presented in Table 7.

Table 7. Multiple Comparisons of Posttest Results

\begin{tabular}{|c|c|c|c|c|c|c|}
\hline \multirow[b]{2}{*}{ (I) groups post } & \multirow[b]{2}{*}{ (J) groups post } & \multirow[b]{2}{*}{$\begin{array}{l}\text { Mean Difference } \\
(\mathrm{I}-\mathrm{J})\end{array}$} & \multirow[b]{2}{*}{$\begin{array}{l}\text { Std. } \\
\text { Error }\end{array}$} & \multirow[b]{2}{*}{ Sig. } & \multicolumn{2}{|c|}{$95 \%$ Confidence Interval } \\
\hline & & & & & $\begin{array}{l}\text { Lower } \\
\text { Bound }\end{array}$ & $\begin{array}{l}\text { Upper } \\
\text { Bound }\end{array}$ \\
\hline \multirow[t]{3}{*}{ Posttest movie group } & Posttest vocab g & $2.26316^{*}$ & .77113 & .042 & .0556 & 4.4707 \\
\hline & Posttest sum g & $3.36842^{*}$ & .77113 & .001 & 1.1609 & 5.5760 \\
\hline & Posttest con $\mathrm{g}$ & $6.00000^{*}$ & .77113 & .000 & 3.7924 & 8.2076 \\
\hline \multirow{3}{*}{$\begin{array}{l}\text { Posttest vocabulary } \\
\text { group }\end{array}$} & Posttest movie g & $-2.26316^{*}$ & .77113 & .042 & -4.4707 & -.0556 \\
\hline & Posttest sum g & 1.10526 & .77113 & .564 & -1.1023 & 3.3128 \\
\hline & Posttest con $g$ & $3.73684^{*}$ & .77113 & .000 & 1.5293 & 5.9444 \\
\hline \multirow[t]{3}{*}{ Posttest summary group } & Posttest movie $\mathrm{g}$ & $-3.36842^{*}$ & .77113 & .001 & -5.5760 & -1.1609 \\
\hline & Posttest vocab g & -1.10526 & .77113 & .564 & -3.3128 & 1.1023 \\
\hline & Posttest con $\mathrm{g}$ & $2.63158^{*}$ & .77113 & .012 & .4240 & 4.8391 \\
\hline \multirow[t]{3}{*}{ Posttest control group } & Posttest movie g & $-6.00000^{*}$ & .77113 & .000 & -8.2076 & -3.7924 \\
\hline & Posttest vocab g & $-3.73684^{*}$ & .77113 & .000 & -5.9444 & -1.5293 \\
\hline & Posttest sum g & $-2.63158^{*}$ & .77113 & .012 & -4.8391 & -.4240 \\
\hline
\end{tabular}

*. The mean difference is significant at the 0.05 level.

The post hoc test revealed that the differences between five comparisons, that is, movie/vocab, movie/summarization, movie/control, vocab/control, and summarization /control had been significant but the difference between pre-reading vocabulary and pre-reading summarization groups had not been significantly different. All these findings compel us to reject our second null hypothesis that had predicted no difference in the effectiveness of the three pre-reading activities at the posttest stage.

There may be situations, however, where researchers want to combine the two approaches in one study, with one independent variable being between-subjects (groups) and the other within subjects (time). This type of hypotheses are tested using Split-plot ANOVA (SPANOVA) alternatively called Mixed between-within subjects ANOVA. Our third hypothesis required such a procedure because we wanted to measure the effect of time on students' gains in different 
groups from posttests to delayed posttests. In other words, we wanted to test the significance of the main effects of the independent variables and their interaction.

Table 8 shows the descriptive statistics of the groups in posttest and delayed posttest.

Table 8. Descriptive Statistics of Posttest and Delayed Posttest Scores

\begin{tabular}{lllll}
\hline & Class type & Std. & \\
& & Mean & Deviation & $\mathrm{N}$ \\
\hline Scores in posttest & Movie & 13.4211 & 1.42657 & 19 \\
& Vocab & 11.1579 & 2.65127 & 19 \\
& Summarizatio & 10.0526 & 2.59216 & 19 \\
& $\mathrm{n}$ & & & \\
& Total & 11.5439 & 2.65969 & 57 \\
\hline Scores in delayed & Movie & 13.1579 & 1.53707 & 19 \\
posttest & Vocab & 11.4737 & 2.71556 & 19 \\
& Summarizatio & 9.1579 & 2.52241 & 19 \\
& $\mathrm{n}$ & & & \\
& Total & 11.2632 & 2.81277 & 57 \\
\hline
\end{tabular}

Apparently, mean differences between the posttest and delayed posttest scores had been very small. However, whether these differences reached the significance level or not was the point that Multivariate Test table, produced as part of SPANOVA output, could tell us.

Like many of parametric tests, SPANOVA has assumptions that should be met before running the test. One of these assumptions is the equality of the covariance matrices which in SPSS output is presented in the Box's table. The $P$ value for this statistic should exceed .001 for us not to violate this assumption. As can be seen in Table 9 , the $P$-value for this statistic is slightly larger than the borderline value, meaning that the assumption had not been violated.

Table 9. Test of Equality of Covariance Matrices

\begin{tabular}{ll}
\hline Box's M & 23.188 \\
$\mathrm{f}$ & 3.658 \\
$\mathrm{Df}$ & 16 \\
Df & 272675.692 \\
Sig. & .002 \\
\hline
\end{tabular}

Box's Test of Equality of Covariance Matricesa

Another assumption of SPANOVA is the equality of error variances or homogeneity of the groups. This assumption as usual is checked by the Levene's Test of Equality of Error Variances. For this statistic we needed non-significant values for both of the posttest and delayed posttest scores. Table 10 shows that the Sig values for the posttest and delayed posttest scores are .072 and. 106 respectively, both non-significant.

Table 10. Test of Equality of Variances

\begin{tabular}{lllll}
\hline & F & df1 & df2 & Sig. \\
\hline Scores in posttest & 2.767 & 2 & 54 & .072 \\
Scores in delayed posttest & 2.340 & 2 & 54 & .106 \\
\hline
\end{tabular}

Multivariate tests show whether the effect of interaction had been significant or not. It should be noted, however, that all these tests do the same thing, so we should look only at one of them, preferably Pillai's Trace or Wilks' Lambda, because these two tests are more powerful than the others in disclosing interactions. Table 11 shows the results of these tests. 
Table 11. Tests of Main and Interaction Effects

\begin{tabular}{lllllllll}
\hline Effect & & Value & F & $\begin{array}{l}\text { Hypothesis } \\
\mathrm{df}\end{array}$ & Error df & Sig. & $\begin{array}{l}\text { Partial Eta } \\
\text { Squared }\end{array}$ \\
\hline Time & Pillai's Trace & .053 & $3.048^{\mathrm{b}}$ & 1.000 & 54.000 & .087 & .053 \\
& Wilks' Lambda & .947 & $3.048^{\mathrm{b}}$ & 1.000 & 54.000 & .087 & .053 \\
& Hotelling's Trace & .056 & $3.048^{\mathrm{b}}$ & 1.000 & 54.000 & .087 & .053 \\
& Roy's Largest Root & .056 & $3.048^{\mathrm{b}}$ & 1.000 & 54.000 & .087 & .053 \\
\hline Time * Class & Pillai's Trace & .149 & $4.726^{\mathrm{b}}$ & 2.000 & 54.000 & .013 & .149 \\
& Wype & Wilks' Lambda & .851 & $4.726^{\mathrm{b}}$ & 2.000 & 54.000 & .013 & .149 \\
& Hotelling's Trace & .175 & $4.726^{\mathrm{b}}$ & 2.000 & 54.000 & .013 & .149 \\
& Roy's Largest Root & .175 & $4.726^{\mathrm{b}}$ & 2.000 & 54.000 & .013 & .149 \\
\hline
\end{tabular}

As can be seen in Table 11, all multivariate test results are significant for interaction between time and class type in our data, meaning that there had been an effect for interaction.

Looking at the tests of within-subjects contrasts and tests of between-subjects effects tells us about the main effects of our independent variables, namely, time and class type. As indicated in Table 12, the main effect of time had been nonsignificant. However, the main effect of class type, as presented in Table 13, had been significant at $P=.000<.05$ level. We should also remember that the interaction between time and class type had also been significant, as we learned from our multivariate tests table. These three pieces of information could help us in rejecting or accepting our third null hypothesis which was directed at investigating the effect of passage of time on the participants' gains. Tables 12 and 13 are given below with the non-significant effect for time alone but significant effects for time and class type interaction plus class type.

Table 12. Main Effect of Time

\begin{tabular}{lllllllll}
\hline \multirow{2}{*}{ Source } & times & $\begin{array}{l}\text { Type III Sum } \\
\text { of Squares }\end{array}$ & df & Mean Square & F & Sig. & $\begin{array}{l}\text { Partial Eta } \\
\text { Squared }\end{array}$ \\
\hline Time & Linear & 2.246 & 1 & 2.246 & 3.048 & .087 & .053 \\
\hline Time * class type & Linear & 6.965 & 2 & 3.482 & 4.726 & .013 & .149 \\
\hline Error(times) & Linear & 39.789 & 54 & .737 & & & \\
\hline
\end{tabular}

Table 13. Main Effect of Class Type

\begin{tabular}{|c|c|c|c|c|c|c|}
\hline \multicolumn{7}{|c|}{ Tests of Within-Subjects Contrasts } \\
\hline \multicolumn{7}{|c|}{ Transformed Variable: Average } \\
\hline Source & Type III Sum of Squares & $\mathrm{df}$ & Mean Square & $\mathrm{F}$ & Sig. & $\begin{array}{l}\text { Partial Eta } \\
\text { Squared }\end{array}$ \\
\hline Intercept & 14824.561 & 1 & 14824.561 & 1498.818 & .000 & .965 \\
\hline Class type & 258.333 & 2 & 129.167 & 13.059 & .000 & .326 \\
\hline Error & 534.105 & 54 & 9.891 & & & \\
\hline
\end{tabular}

These results reject our third null hypothesis by suggesting a change over time which had been the result of both instruction type and its interaction with time but not time alone.

\section{Discussion and Conclusion}

The first research question was "Do pre-reading activities affect students' reading comprehension from pretests to posttests?" The analysis of data revealed that pre-reading activities, in general, improved students' comprehension of texts because pre-reading strategies activate students' prior knowledge. Therefore, the findings advocated the use of pre-reading activities which is in line with the findings of other research (Chang, 1990; Maghsoudi, 2012; Mihara, 2011; Zhaohua, 2004). In addition, the study findings implied the employment of pre-reading activities in reading classes as a motivational factor. Motivation, according to Ur (2007) plays an important role in foreign language learning. 
The second research question was "Is there any difference in the effectiveness of the three pre-reading activities of watching movies, vocabulary presentation, and pre-reading summarization?". Analysis of the results provided evidence that there were significant differences among the groups experiencing different pre-reading activities. The moviewatching group outperformed the other two groups. This finding is consistent with the results of Gebhard (1987) whose study showed that by providing background knowledge on a reading through exposing students to short movies, teachers can facilitate successful reading comprehension. This finding also seemed to be in line with the results of studies which showed that watching movies has stronger effect on L2 reading comprehension (e.g., Gambrell \& Jawits, 1993; Ismaili, 2013). Movies are possibly more entertaining and engaging to students. According to Gambrell and Jawits (1993), movies provide delightful occasions for students to develop background knowledge and to combine it with their own understanding of a story or concept. The four-skill activities in the classroom are furthermore activated by background knowledge that is provided by movies in EFL classrooms, as Herron and Hanley (1992) put it, which is necessary for stimulating students.

Results also revealed that the vocabulary group's performance in the posttest had been better than the summarization group's performance. Unlike the findings of this study, Carrell (1984) believes that teaching new vocabulary is only effective if it is "integrated with both the student's preexisting knowledge and other pre-reading activities designed to build background knowledge" (p. 337). In addition to this, Carrell (1984) believes that vocabulary and schemata should be developed by "pre-teaching vocabulary and background knowledge concurrently" (p. 340). It is possible that if one group had received vocabulary presentation and pre-reading summarization simultaneously, more significant results might have emerged.

Regarding the third research question, which aimed at investigating the effect of time, the results rejected the null hypothesis, that is, decrease in the students' scores in the delayed posttest is the result of the passage of time only. Contrary to this, this study produced evidence in favor of the impact of time and class type jointly on the reading comprehension of the EFL learners. That is, time and the kind of pre-reading activity together affected the learners' reading comprehension and decrease in students' scores was not solely the result of time passage. This is in line with Day's (1982) claim that students' curiosity can be stimulated by visuals as they attempt to analyze the associated concepts with pictures. This stimulation of curiosity might then more effectively focus learners' attention on the subject matter being introduced, which in the long run might lead to an even more effective acquisition of information. When applied to reading comprehension the findings of the present study demonstrate that increased levels of attention on key words and main concepts before reading the passage can persist in learners' working memory, hence making the associated meanings more memorable.

From the discussion of findings, one can conclude that pre-reading activities have positive effects on students' performance in reading comprehension. The present study agrees with Langer (1981) and provides more empirical support to the fact that pre-reading activities boost students' interest and help them construct mental models for the incoming text. Taken all points together, the results reveal that there might be differences between students' performance in reading comprehension with regard to the type of pre-reading activity they are exposed to. The findings also show that the most effective pre-reading activity is movie-watching. These results are in agreement with those of Mcnamara et. al., 2011. Using pre-reading strategies that activate students' prior knowledge, for instance movie watching, will enable students to connect to the content and comprehend the material.

\section{References}

Anjomshoa, L., \& Sadighi, F. (2015). The effects of three pre-reading activities (text summary, vocabulary definition, and pre-passage questions) on the reading comprehension of Iranian EFL learners. International Journal of Education and Pedagogical Sciences, 3(2), 401-417.

Ausubel, D. P. (1963). Some psychological considerations in the objectives and design of an elementary school science program. Science Education, 47(3), 278-284.

Bilokcuoglu, L. H. (2011). The effects of pre-reading activities in EFL classes on students' reading comprehension. EUL Journal of Social Sciences, 2(2), 179-197.

Carrell, P. L. (1984). Schema theory and ESL reading: Classroom implications and applications. The Modern Language Journal, 63, 332-343.

Chang, Y. (1990). Schema theory and ESL reading. (Unpublished master's thesis). Available from ProQuest Dissertations. (UMI No. 1342221)

Cook, G. (1997). Key concepts in ELT: Schemas. ELT Journal, 5(1), 86-94.

Day, H. I. (1982). Curiosity and the interested explorer. Performance and Instruction, 21(4), 19-22.

Gambrell, L. B., \& Jawitz, P. B. (1993). Mental imagery, text illustrations, and children's story comprehension and recall. Reading Research Quarterly, 28(3), 265-273.

Gebhard, J. (1987). Successful comprehension: What teachers can do before students read. English Teaching Forum, 2 , 24-25.

Haque, M. M. (2010). Do pre-reading activities help learners comprehend a text better? (Unpublished dissertation), BRAC University.

Herron, C., \& Hanley, J. (1992). Using video to introduce children to a foreign culture. Foreign Language Annals, 25, 419-426. 
Hyde, C. L. (2002). A comparison of the effect of two types of pre-reading vocabulary lists on learner reading comprehension: Glossed difficult words vs. key cohesive lexical chains. (Unpublished master's thesis), University of Surrey.

Ismailia, M. (2013). The effectiveness of using movies in the EFL classroom a study conducted at south east European university. Academic Journal of Interdisciplinary Studies, 2(4), 120-132.

Jahangard, A., Moinzadeh, A., \& Karimi, A. (2011). The effect of grammar vs. vocabulary pre-teaching on EFL learners' reading comprehension: A schema theoretic view of reading. Journal of English Language Teaching and Learning, 8, 91-113.

Johnson, P. (1982). Effect on reading comprehension of building background knowledge. TESOL Quarterly, 16(4), 503-160.

Langer, J. A. (1981). From theory to practice: On pre-reading plan. J. Reading, 25, 152-156.

Maghsoudi, N. (2012). The impact of schema activation on reading comprehension of cultural texts. Canadian Social Sciences, 8(5), 196-201.

McNamara, D. S., Ozuru, Y., \& Floyd, R. G. (2011). Comprehension challenges in the fourth

Mihara, K. (2011). Effect of pre-reading strategies on EFL/ESL reading comprehension. TESL Canada Journal, 28(2), 51-73.

Norris, S. P. \& Phillips, L. M. (1987). Explanations of reading comprehension: Schema theory and critical thinking theory. Teachers College Record, 7(2), 281-306.

Tudor, L. (1990). Pre-reading format and learner proficiency level in L2 reading comprehension. Journal of Research in Reading, 20, 93-106.

Ur. P. (2007). A course in language teaching practice and theory. Cambridge: Cambridge University Press.

Yusuf, H. (2011). The effect of pre-reading activities on students' performance in reading comprehension in senior secondary school. International Research Journals, 2(9), 1451-1455.

Zhaohua, S. (2004). Effects of previewing and providing background knowledge on EFL reading comprehension of American documentary narratives. TESL Reporter, 37(2), 50-63. 